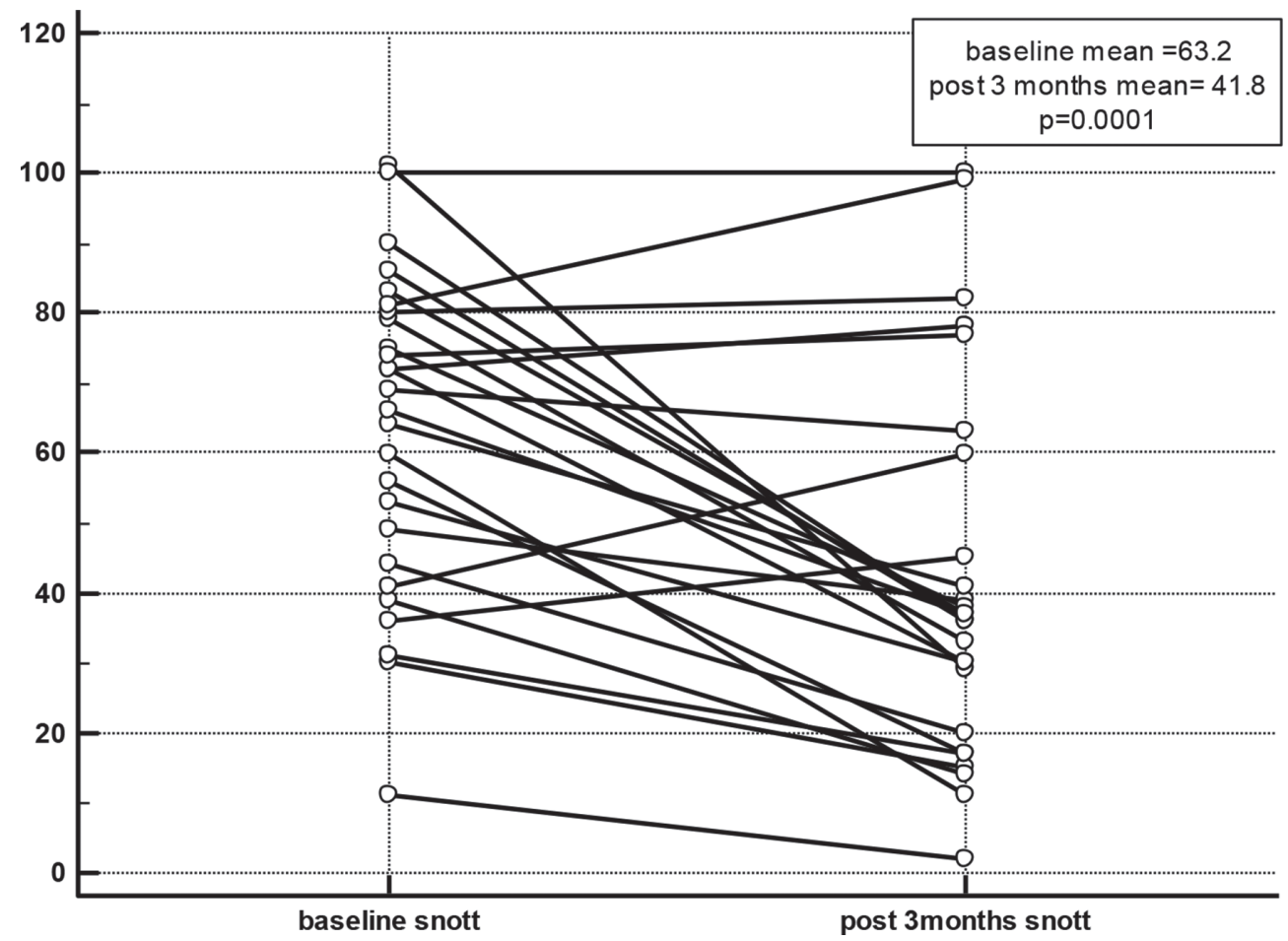

Abstract P127 Figure 1 Changes in SNOTT score with nasal irrigation treatment

improved. Mean initial ACQ $3.42 \pm 1.39$ compared to $2.62 \pm 1.58$ post treatment $(\mathrm{p}=0.01)$. Usage ranged from $\mathrm{BD}$ to $3-5$ times per week. $17 \%(5 / 30)$ of patients reported side effects: headache (2) sneezing(1) Nose bleed(1) LBP(1) three patients stopped treatment due to the side effect.

Conclusion After three months of nasal irrigation $88 \%$ of patients reported improved nasal symptoms, 62\% reported improved chest symptoms, there were statistically significant improvements in mean snott 22 and ACQ scores. Nasal irrigation is therefore an effective and inexpensive intervention, with few side effects, in the treatment of rhinosinus and related asthma symptoms and should be advocated in severe asthma clinics.

\section{P128 COMPARISON OF SAFETY AND EFFICACY OF AIRWAY CLEARANCE TECHNIQUES, HYPERTONIC SALINE AND BRONCHOSCOPY IN A SEVERE ASTHMA SERVICE}

RL Sheehan, RM Niven, DM Ryan. University Hospital of South Manchester NHS Foundation Trust, Manchester, UK

\subsection{6/thoraxjnl-2016-209333.271}

Introduction There is limited research into airway clearance techniques (ACT) and high dose hypertonic saline 7\% (HS-7) tolerance and safety in adults with severe asthma. Clinical benefit of sputum eosinophils and microbiology in severe asthma is well established. Airway samples can be obtained via spontaneous production, using physiotherapy (ACT, sputum induction $(0.9-4.5 \%$ traditionally) or via bronchoscope. ${ }^{1}$ There are concerns with regards to risk of asthma exacerbation with sputum induction and bronchoscopy.

Objective assess and compare safety and efficacy of ACT, HS-7 and bronchoscopy in patients attending severe asthma clinic.

Method We assessed consecutive patients attending a severe asthma service at a tertiary referral centre who had undergone ACT and or HS-7 challenge and or bronchoscopy during 20142016. In total, 330 procedures were performed by a chest physiotherapist (ACT/HS-7) and consultant respiratory physician (bronchoscopy). Data was gathered on procedure tolerance and sample yield. Indications for undergoing HS-7 included sample procurement or challenge test for home nebulisation. Bronchoscopy was performed for a variety of indications, not limited solely to sample procurement.

Results 114 patients completed ACT, 109 underwent HS-7 and 99 had bronchoscopy (Table 1). 65 of 104 (62.5\%) in the physiotherapy group had no prior spontaneous sputum samples. Of these, 46 (71\%) had HS-7 induction and 19 (29\%) had successful ACT. 25 of 77 (32\%) patients in the physiotherapy group had positive bacterial culture, and 18 of 38 (47\%) positive aspergillus PCR. ACT, HS-7 and bronchoscopy were well tolerated. All 114 (100\%) patients tolerated ACT from an asthma perspective. 8 of 117 (7\%) of HS-7 group and 8 of $99(8 \%)$ of bronchoscopy group required rescue salbutamol nebulisation without further complications. Two patients had severe asthma exacerbations in the bronchoscopy group, 2 of 99 (2\%), and required hospitalisation at ward level, This risk was similar to previously reported data. 
Abstract P128 Table 1 Safety comparison of respiratory interventions in patients attending a severe asthma service

\begin{tabular}{llll}
\hline & $\begin{array}{l}\text { Airway clearance } \\
\text { techniques } \\
\mathrm{n}(\%)\end{array}$ & $\begin{array}{l}\text { Hypertonic saline- } \\
\mathbf{7} \% \text { challenge } \\
\mathrm{n}(\%)\end{array}$ & $\begin{array}{l}\text { Bronchoscopy } \\
\mathbf{n}(\%)\end{array}$ \\
\hline $\begin{array}{l}\text { No asthma symptoms } \\
\text { Bronchospasm requiring } \\
\text { nebulised SABA }\end{array}$ & $\begin{array}{l}114(100 \%) \\
\begin{array}{l}\text { Severe Asthma } \\
\text { Exacerbation }\end{array}\end{array}$ & $\begin{array}{l}109(93 \%) \\
8(0 \%)\end{array}$ & $89(90 \%)$ \\
$\begin{array}{l}\text { Total } \\
\text { Short acting beta-agonist }\end{array}$ & 114 & $0(0 \%)$ & $8(8 \%)$ \\
\hline
\end{tabular}

Conclusion In patients attending a severe asthma clinic physiotherapy techniques (ACT and HS-7) were safe and effective. Bronchoscopy had similar requirement for rescue salbutamol nebulisation compared to HS-7, but a higher risk (2\%) of severe asthma exacerbation.

\section{REFERENCE}

1 Brinke AT, et al. Sputum induction in severe asthma by standardised protocol. AJRCCM 2001;164(5):749-753.

\section{P129 FUNGAL CONTAMINATION OF VALVED HOLDING CHAMBERS (VHCS): POTENTIAL TO PREVENT, AND EFFECT ON DRUG DELIVERY}

${ }^{1}$ MJ Sanders, ${ }^{1} \mathrm{R}$ Bruin, ${ }^{2} \mathrm{CH}$ Tran. ${ }^{1} \mathrm{Clement}$ Clarke International Ltd, Harlow, UK; ${ }^{2} \mathrm{i} 2 \mathrm{C}$ Pharmaceutical Services, Cardiff, UK

\subsection{6/thoraxjnl-2016-209333.272}

Introduction and objectives Able Spacerâ-2 VHC (AS2) is one of many accessory devices available to improve pressurised metered dose inhaler (pMDI) drug delivery, but uniquely includes $\mathrm{a} \sim 1 \mathrm{wt} \%$ body polymer silver ion additive $(\sim 1 \% \mathrm{Ag}+)$ to combat microbial growth and reduce static. Drug-specific bacterial growth on VHC polymers ${ }^{1}$ and the bacterial growth-reducing effects of the $\mathrm{Ag}+$ polymer are known. ${ }^{2}$ The fungal pathogen
Aspergillus fumigatus causes serious pulmonary disease. We assessed the effect of $4 \% \mathrm{Ag}+$ on fungal activity and, subsequently, drug delivery characteristics.

Methods Determination of fungal sporicidal activity was via modified ISO22196:2011 using flat body polymer discs $(n=3)$ of AS2 1\% Ag+ and AS2 4\% Ag+, and sterile Control (same polymer minus $\mathrm{Ag}+, \mathrm{n}=6) .100 \mathrm{~mL}$ A. fumigatus $\left(5.0 \times 10^{5}\right.$ spores $/ \mathrm{mL}$ distilled water) was pipetted onto disc surfaces. Samples were incubated for $24 \mathrm{~h}$ at $35^{\circ} \mathrm{C} / \geq 95 \%$ relative humidity, with silver ions neutralised thereafter. Colony forming units (CFU) were enumerated by spiral dilution and converted to CFU/ $\mathrm{cm}^{2}$. Aerosol performance of salbutamol (as salbutamol sulphate) pMDI (Ventolinâ Evohaler, GSK) through AS2 VHC ( 1\% Ag + as standard) and a newly-developed AS2 4\% Ag+ VHC was assessed through a Next Generation Impactor (NGI) at $30 \mathrm{~L} / \mathrm{min}$. pMDIs and NGI were operated, and drug determinations made, using standard procedures.

Results 24 h geometric mean $\log _{10}$ A. fumigatus $\mathrm{CFU} / \mathrm{cm}^{2}$ were $4.2 \times 10^{3}$ (Control), $2.8 \times 10^{3}(\sim 1 \% \mathrm{Ag}+)$, and $4.5 \times 10^{2}$ $(4 \% \mathrm{Ag}+)$, representing $\log _{10}$ and $\%$ reductions from Control of $0.2(34 \%)$ and $1.0(89 \%)$ for $\sim 1 \% \mathrm{Ag}+$ and 4\% Ag+. Key salbutamol aerosol performance data were emitted dose $(\mathrm{mg})$ $95.9 \pm 11.0$ and $94.9 \pm 9.1$; fine particle fraction $(\%<5.0$ $\mathrm{mm}) 54.0 \pm 4.3$ and $53.6 \pm 1.9$; and fine particle dose $(\mathrm{mg}<5.0 \mathrm{~mm}) 52.0 \pm 8.7$ and $50.7 \pm 3.8$ for AS2 $\sim 1 \% \mathrm{Ag}+$ and AS2 4\% Ag + respectively. NGI recovery (Figure 1) profiles were very similar, including the VHC component: $38.9 \pm 4.2$ (AS2 1\% Ag+) and 40.2 \pm 5.3 (AS2 4\% Ag+).

Conclusions Use of $4 \% \mathrm{Ag}+$ additive did not affect salbutamol aerosol performance and showed greater effect on A. fumigatus spored activity in vitro. VHC fungal Candida spp. and nebuliser Aspergillus spp. have been identified. The moist, anti-static setting of the Chamber may support and, of more concern, promote aerosolisation into the lungs of fungal material. Further research and understanding are necessary.

\section{REFERENCE}

1 Sanders. PCRM 2016;26(16022):16.

2 Sanders MJ, et al. P87 Klebsiella Pneumoniae Survival On Plastic Valved Holding Chamber Bodies. Thorax 2014;69(Suppl 2):A114.

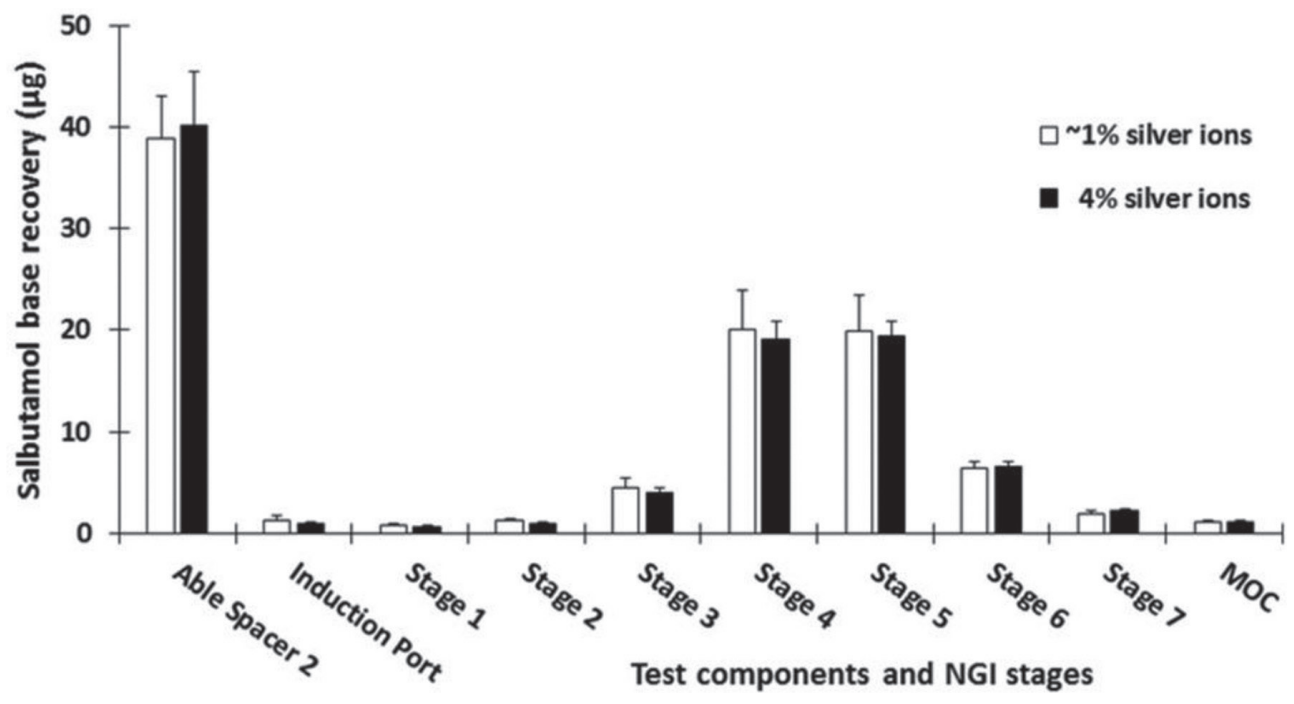

Abstract P129 Figure $1 \mathrm{NGI}$ recovery profiles for salbutamol via AS2 1\% Ag+ and AS2 4\% Ag+ (mean values $\pm S D, n=5$ ) 